\title{
MONITORING OF SMALL CHANNEL SLABS IN RAILWAY TRACK SCIENCE
}

\author{
ALEXANDER TESAR $^{1}$, JOZEF MELCER ${ }^{2}$ AND DANIELA KUCHAROVA ${ }^{2}$
}

Presented is the adoption of fractal approaches for identification and monitoring of small channel slabs in advanced railway track science. The assessment of the problem is presented. The analysis is based on wave approaches. Some structural applications and testing in situ are submitted.

Keywords: fractals, identification, monitoring, structural response, small channel slab, testing, wave approach

\section{Introduction}

Some properties of the small channel slabs used in advanced railway engineering are studied. The identification and monitoring of such elements is done by fractal modelling.

The fractal object has in essence the same configuration irrespective of its blowing up. This idea increased to infinity by "the motive in the middle of motive in the middle of another motives" is called "self-similarity" (recursion or picture in the picture). The shape of fractal is still the same in any gauge of length. Such approach, with automatic variability of the element mesh in space and time, is advantageous for the assessment of ultimate response of advanced small channel slabs.

The fractals can be used for modelling of dynamic systems with simplified patterning of tree or plant branching. However, some structures exist which don't correspond with simple geometric figures. Their feature is that they consist of parts and each part is the miniature of the whole. There exist geometric objects created as progression limits of the sets formed into figures with decreasing gauge of the basic pattern. One of them is the cellular automat as a dynamic system formed by a cell structure in the $\mathrm{N}$-dimensional space, the most often $N=2$, so called 2D CA. The cells create even lattice. Every cell can assume one of $K$ possible states in the time step studied. The values of the cell states in the next time steps are specified by local transitional function. The independent variable is the actual state of investigated cell and of all surrounding cells.

The aplication of CA-modeling for assessment of small channel slabs in railway track science is made below. The motion of vehicles on the rail is modeled by 2D CA. The trails are modeled by traffic circles in which 2D CA follows each other.

\footnotetext{
${ }^{1}$ Institute of Construction and Architecture, Slovak Academy of Sciences, Dubravska cesta 9, 84503 Bratislava 45, Slovak Republic, e-mail: alexander.tesar@savba.sk

${ }^{2}$ Department of Structural Mechanics, University of Zilina, Univerzitna 1, 01026 Zilina, Slovak Republic, e-mail: jozef.melcer@fstav.uniza.sk, daniela.kucharova@fstav.uniza.sk
} 


\section{Analysis}

Recent advances in mechanics have submitted all necessary tools for fractal modelling of small channel slabs in present railway track science. Real time monitoring is used for the assessment of the response of such structures subjected to forcing by moving trains. The state of small channel slab is estimated by measurement and identification. The presumption of standing waves with exchange of potential and kinetic energies appearing in fractal modelling is adopted.

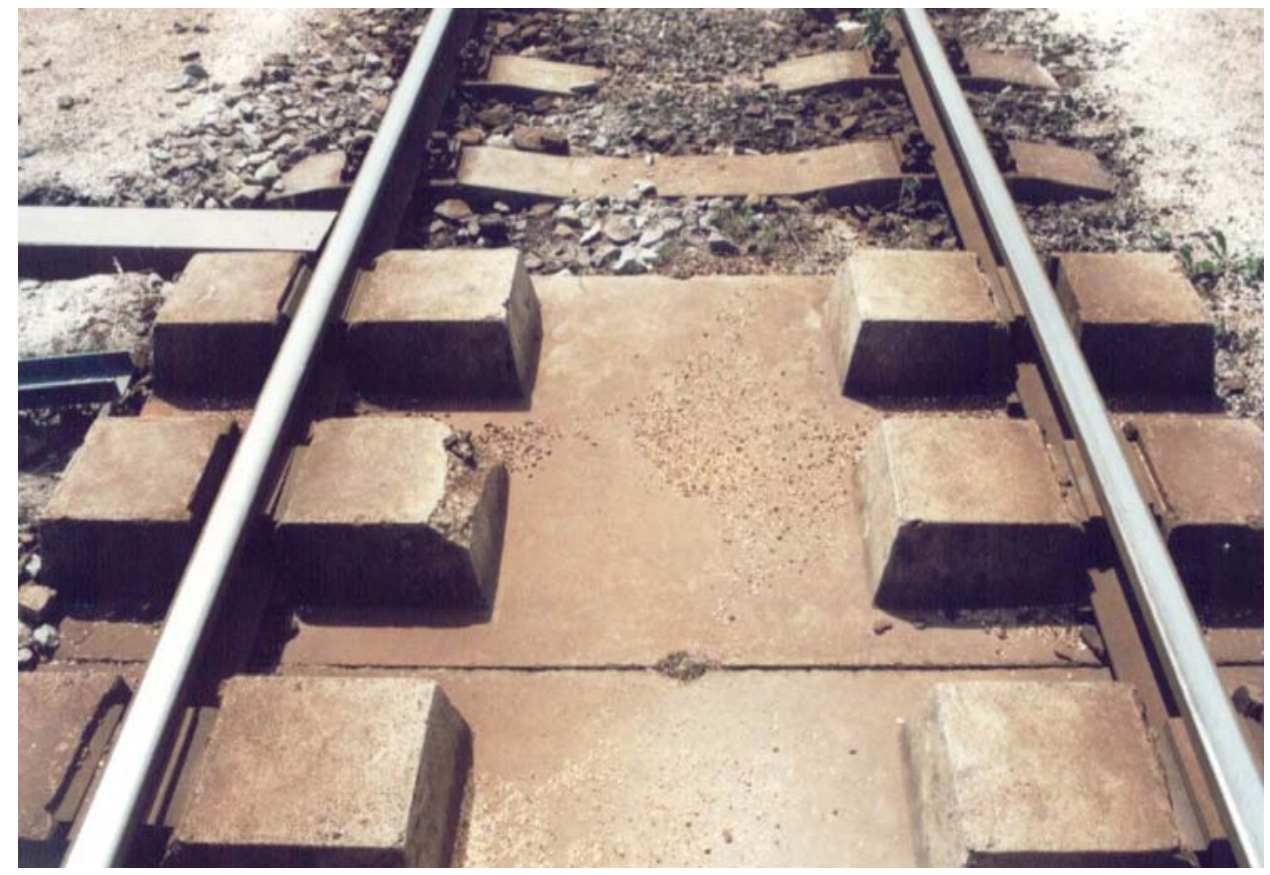

Figure 1. View of the small channel slab studied

The small channel slab in Figure 1 is radiated by waves and modelled by 2D CA. The response is propagated into all elements of the slab and rail. The wave propagation has two physical aspects - the source of waves and the medium where they are propagated. The waves initiated in the source and filtered into a slab are specified by spectral evolution based on definitions:

1. Each forcing function $x(\mathrm{t})$ is interpreted in integral form by

$$
x(t)=\int e^{i \omega t} d A(\omega)
$$

with orthogonal complex process $A(\omega)$ and with the frequency $\omega$.

2. The linear transformation $y(\mathrm{t})$ of function $x(\mathrm{t})$ is

$$
y(t)=\int H(i \omega) e^{i \omega t} d A(\omega)
$$

with admittance function $H(\omega)$. 
3. The spectral density of functions $x(\mathrm{t})$ and $y(\mathrm{t})$ is

$$
\mathrm{S}_{\mathrm{y}}(\omega) / \mathrm{S}_{\mathrm{x}}(\omega)=|\mathrm{H}(\mathrm{i} \omega)|^{2}
$$

The stationary waves are emitted from source with complex amplitude $F\left(\omega, z_{0}\right)$ and with longitudinal dimension $z=z_{0}$. The wave superposition is given by

$$
w_{i}(t, z)=\int e^{-i \omega t} e^{i r(\omega z)} d F\left(\omega, z_{0}\right)
$$

Possible inhomogeneity in the small channel slab is touched by propagating waves. The response spectrum of inhomogeneity is given by

$$
\mathrm{S}(\omega, 0)=\mathrm{S}\left(\omega, \mathrm{z}_{0}\right)|\mathrm{H}(\omega, 0)|^{2} \mathrm{e}^{-2 \operatorname{Im}[\mathrm{r}(\omega)]}
$$

The response spectrum obtained is used for specification of updated physical parameters in identification and monitoring of small channel slabs studied.

\section{Identification}

Forcing of the small channel slab by white noise processes $e_{\mathrm{x}}\left(\mathrm{t}_{\mathrm{k}}\right)$ and $e_{\mathrm{m}}\left(\mathrm{t}_{\mathrm{k}}\right)$ is assumed. The time equivalents $\Delta \mathrm{x}\left(\mathrm{t}_{\mathrm{k}+1}\right)$ and $\Delta y\left(\mathrm{t}_{\mathrm{k}+1}\right)$ are given by

$$
\begin{aligned}
& \Delta \mathrm{x}\left(\mathrm{t}_{\mathrm{k}+1}\right)=\mathrm{F} \Delta \mathrm{x}\left(\mathrm{t}_{\mathrm{k}}\right)+\mathrm{B} \mathrm{e}_{\mathrm{x}}\left(\mathrm{t}_{\mathrm{k}}\right) \\
& \Delta \mathrm{y}\left(\mathrm{t}_{\mathrm{k}+1}\right)=\left(\mathrm{G}_{1}+\mathrm{G}_{2}\right) \mathrm{A} \Delta \mathrm{x}\left(\mathrm{t}_{\mathrm{k}}\right)+\mathrm{e}_{\mathrm{m}}\left(\mathrm{t}_{\mathrm{k}}\right)
\end{aligned}
$$

where the state vector $\Delta x$ contains the elements related to specification of stochastic properties of input data and of system matrices $F, B$ and $G$.

The covariance matrices for assumed forcing are $R_{\mathrm{x}}\left(\mathrm{t}_{\mathrm{i}}\right)$ and $R_{\mathrm{xm}}\left(\mathrm{t}_{\mathrm{i}}\right)$. The relation between covariance matrices $Y\left(\mathrm{t}_{\mathrm{i}}\right)$ of the process $y\left(\mathrm{t}_{\mathrm{k}}\right)$ and the system matrices of the time model is given by

$$
Y_{k}\left(t_{i}\right)=G F_{k-1} M\left(t_{i}\right)
$$

with

$$
M\left(t_{i}\right)=F R_{x}\left(t_{i}\right) G^{T}+B R_{x m}\left(t_{i}\right)
$$

The Hankel matrix is established by adoption of covariance matrices $Y_{\mathrm{k}}\left(\mathrm{t}_{\mathrm{i}}\right)$. The identification is given by:

1. Specification of the Hankel matrix of the problem.

2. Adoption of singular value decomposition of the Hankel matrix by

$$
\mathrm{H}(\mathrm{p})=\mathrm{U} \mathrm{T}^{2} \mathrm{~V}^{\mathrm{T}}
$$

with $U$ and $V$ as orthogonal matrices and $T$ as diagonal and semidefinite matrix of singular values.

3. Specification of the system matrices by

$$
\begin{aligned}
& \mathrm{F}=\mathrm{T}^{-1} \mathrm{U}^{\mathrm{T}} \mathrm{H}(\mathrm{p}) \mathrm{V} \\
& \mathrm{M}=\mathrm{T} \mathrm{V}^{\mathrm{T}} \mathrm{E}_{\mathrm{n}} \\
& \mathrm{G}=\mathrm{E}_{\mathrm{n}} \mathrm{U} \mathrm{T}
\end{aligned}
$$


with

$$
\mathrm{E}_{\mathrm{n}}=\left[\begin{array}{lllll}
\mathrm{I}_{\mathrm{n}} & 0 & 0 & \ldots & 0
\end{array}\right]
$$

4. Analysis of the eigenvalue problem established by the ( $m \times m$ )-upper left submatrix of the $(n \times n)$-system matrix $F$.

5. Calculation of modal parameters from eigenvalues and eigenvectors obtained.

6. Repeated calculations from the step 4 for increasing system submatrix of dimension m.

The response of the slab is calculated in advance. The forcing $P_{\mathrm{j}}(\mathrm{t})$ located in node $j(\mathrm{j}=1,2$, $3, \ldots \mathrm{n})$ in time $t$ is considered. The response function in node $\mathrm{i}$ is given by $X_{\mathrm{i}}(\mathrm{t})(i=1,2,3, \ldots$ $m)$. The symbol $g_{\mathrm{ij}}(\omega)$ specifies the spectral response function in node i due to unit impulse $e^{\mathrm{i} \omega t}$ given by

$$
X(t)=\int g(t) P(t) d t
$$

with the vectors $X(\mathrm{t})$ and $P(\mathrm{t})$ of the functions $X_{\mathrm{i}}(\mathrm{t})$ and $P_{\mathrm{i}}(\mathrm{t})$, respectively. The symbol $g(\mathrm{t})$ is the $(m \times m)$-matrix of functions $g_{\mathrm{ij}}(\omega)$. The response is given by

$$
\mathrm{M}_{\mathrm{Y}}(\omega)=\mathrm{N}(\omega) \mathrm{M}_{\mathrm{P}}(\omega)
$$

where $N(\omega)$ is the complex transfer function of the small channel slab studied and $M_{\mathrm{Y}}(\omega)$ is the response transform of the forcing $M_{\mathrm{P}}(\omega)$. The complex transfer function $N(\omega)$ defines the spectral characteristics of the small channel slab under adoption of above mentioned identification approach and specifies the amplitude and phase shift of structural response related to harmonic components of forcing adopted. In scope of the wave analysis an updated structural geometry is given by a multigrid space fractal mesh. In updated Lagrangian formulation of motion the major geometric nonlinearities are implemented into coordinate transformations of the fractal mesh used. The fractal mesh works with dynamic variability of the mesh sizes adopted (Tesar, 1985 and 1988).

\section{Application}

The assessment of vertical accelerations in typical small channel slab initiated by train forcing was studied. The slab response forced by the loc running with various velocities was analysed. In addition, the testing of the slab subjected to impulse forcing was made. The motion of the loc on the rail was modelled by 2D CA. The small channel slab was modelled by the circles in which 2D CA followed each other. Testing approach and equipment adopted are described below.

The calculated modes of the slab vibration are in Figure 2. The measurement equipment adopted is in Figure 3. The location of accelerometers as well as the position of the impulse forcing, are in Figure 4. 

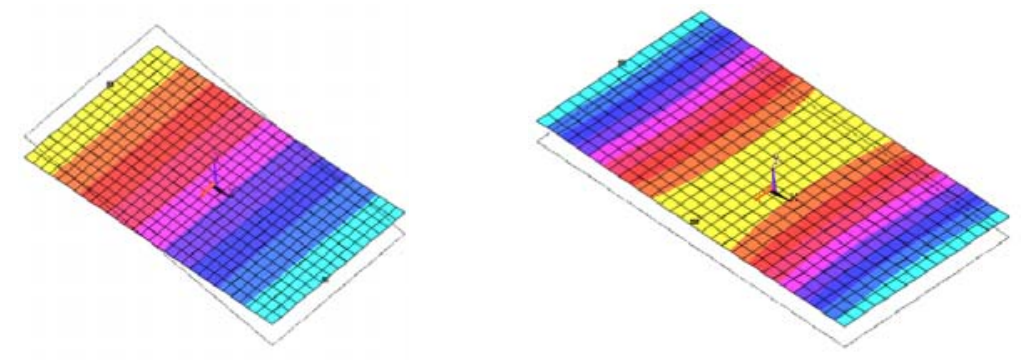

$$
\mathbf{j}=\mathbf{1}
$$

$$
\mathbf{j}=\mathbf{2}
$$
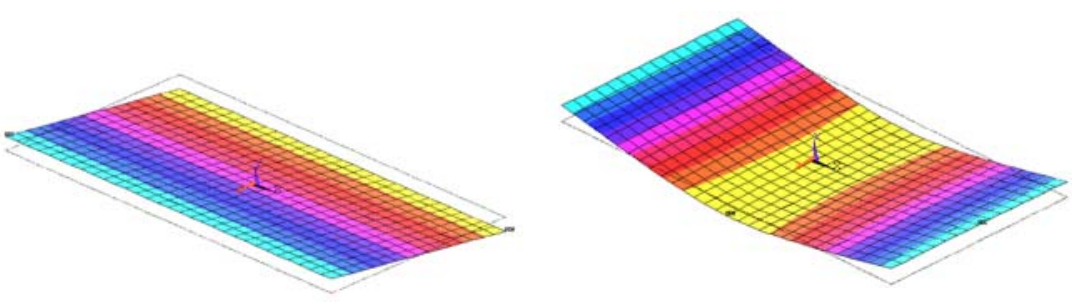

$$
\mathbf{j}=\mathbf{3}
$$

$$
\mathbf{j}=\mathbf{4}
$$
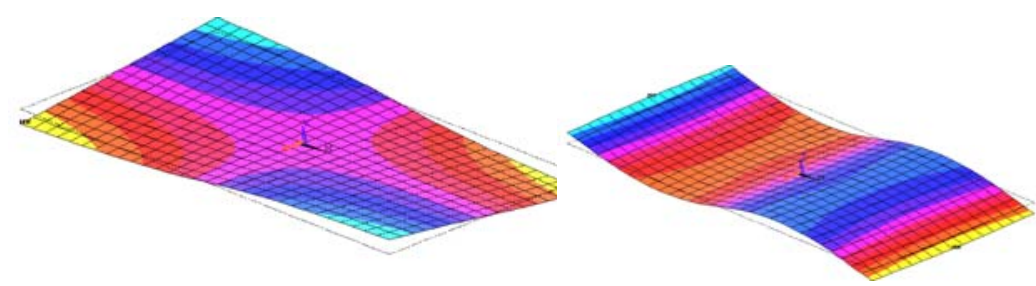

$$
\mathbf{j}=\mathbf{5}
$$

$$
\mathbf{j}=\mathbf{6}
$$

Figure 2. Natural modes $\mathrm{j}=1-6$

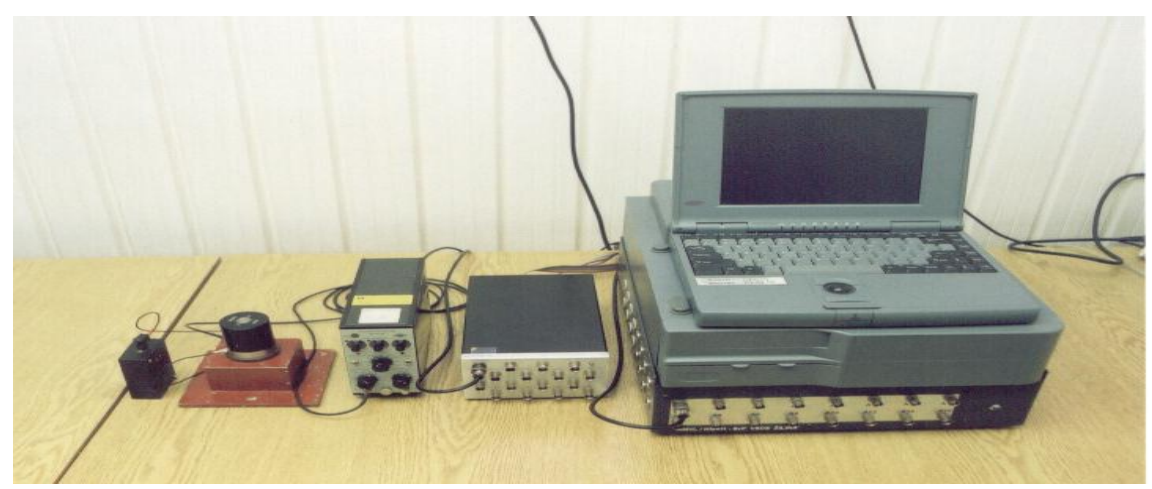

Figure 3. Measuring equipment used for measuring of accelerations 


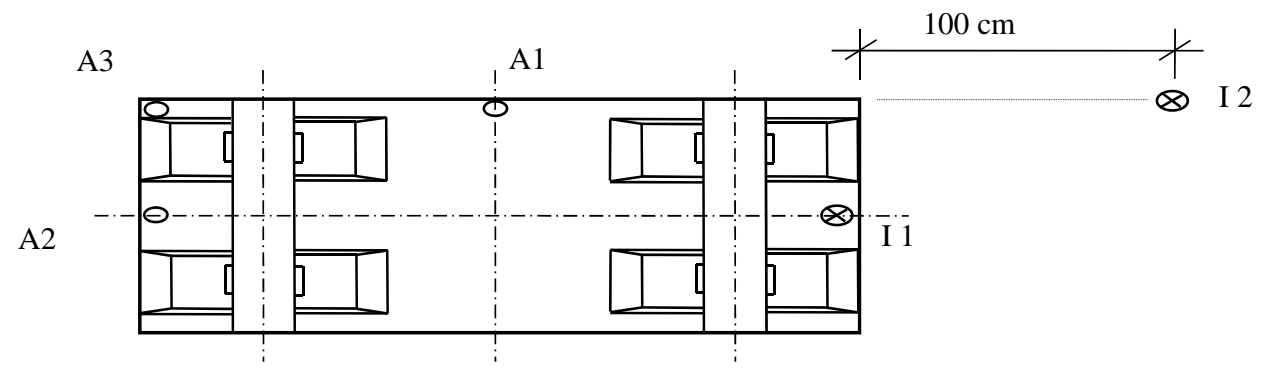

Figure 4. Location of accelerometers and impulse loads
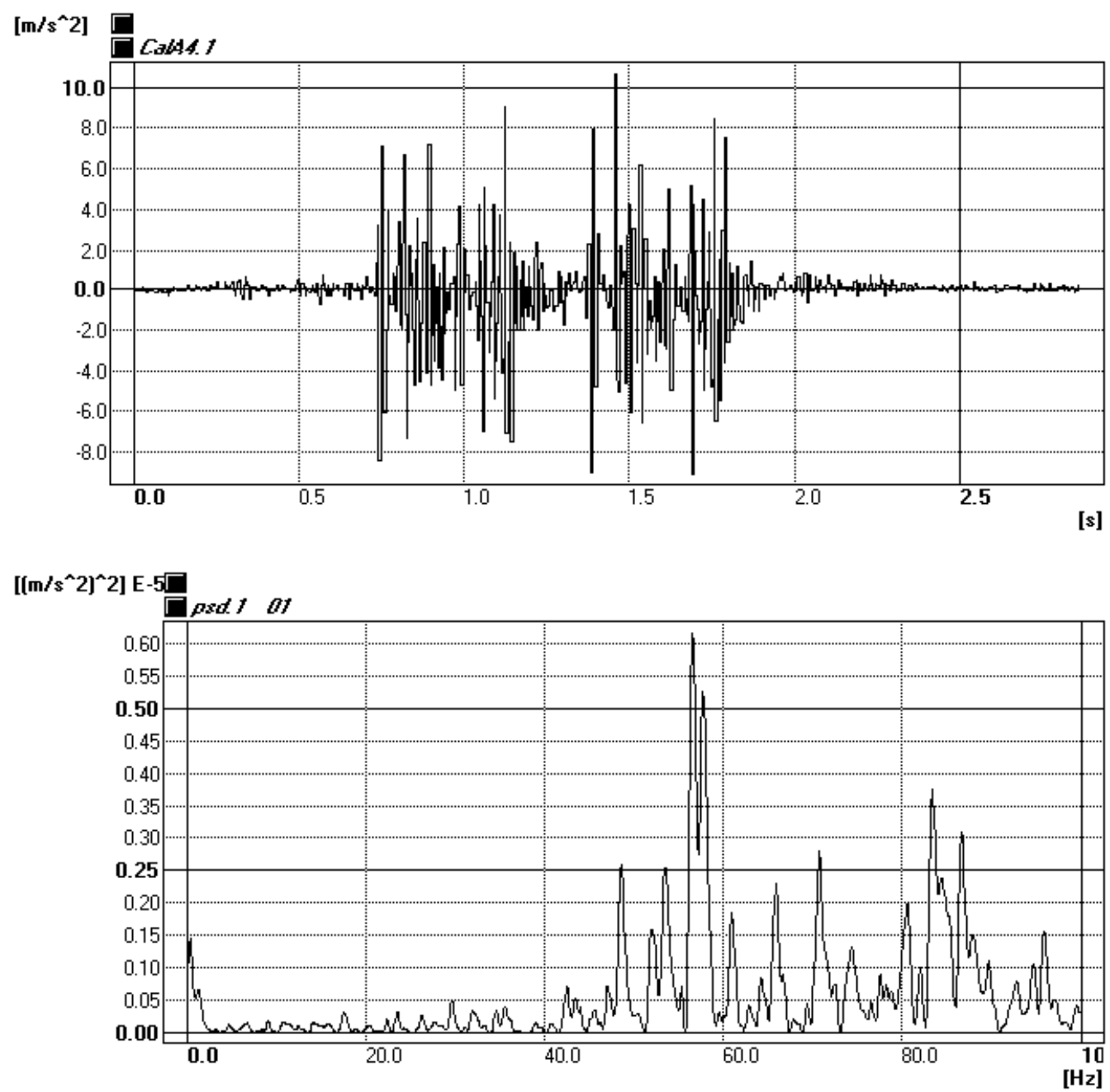

Figure 5. Time history of acceleration and power spectrum $(38.28 \mathrm{~km} / \mathrm{h}$, sensor A3, dominant frequency $56.37 \mathrm{~Hz}$ ) 
In scope of the frequency analysis the corresponding power frequency spectra were obtained. The frequency analysis is plotted in Figure 5. The accelerations in gauge A3 (see Fig. 4) caused by the run of the loc with speed $38.28 \mathrm{~km} / \mathrm{h}$, are in top part of Figure 5 . The corresponding power frequency spectrum, with measured dominant frequency $56.37 \mathrm{~km} / \mathrm{h}$ (calculated one is $56.72 \mathrm{~Hz}$ ), is in down part of Figure 5. The dominant frequency $56.37 \mathrm{~Hz}$ was found in scope of the frequency analysis of accelerations in gauges A1 and A2. The power frequency spectrum, evaluated on the basis of accelerations in gauge A1 for the same loc run, is in Figure 6.

Similar results were obtained in the analysis of the slab accelerations due to impulse loads adopted. In top part of Figure 7 is the time response in gauge A1 corresponding to impulse forcing. In down part of Figure 8 is the corresponding power frequency spectrum with measured dominant frequency $56.11 \mathrm{~Hz}$ (calculated one is $56.47 \mathrm{~Hz}$ ). The response of the slab accelerations registered in the gauge $\mathrm{A} 1$ is in top part of Figure 8 . The forcing was made by impulse acting on the soil surface and distanced $1 \mathrm{~m}$ from the slab edge. In down part of Figure 8 is the corresponding power frequency spectrum with dominant peaks $33.03 \mathrm{~Hz}$ and $56.15 \mathrm{~Hz}$ (calculated values were $33.58 \mathrm{~Hz}$ and $57.22 \mathrm{~Hz}$, respectively). The frequency $33.03 \mathrm{~Hz}$ coincides with dominant frequency of the surface deformation wave under small channel slab.

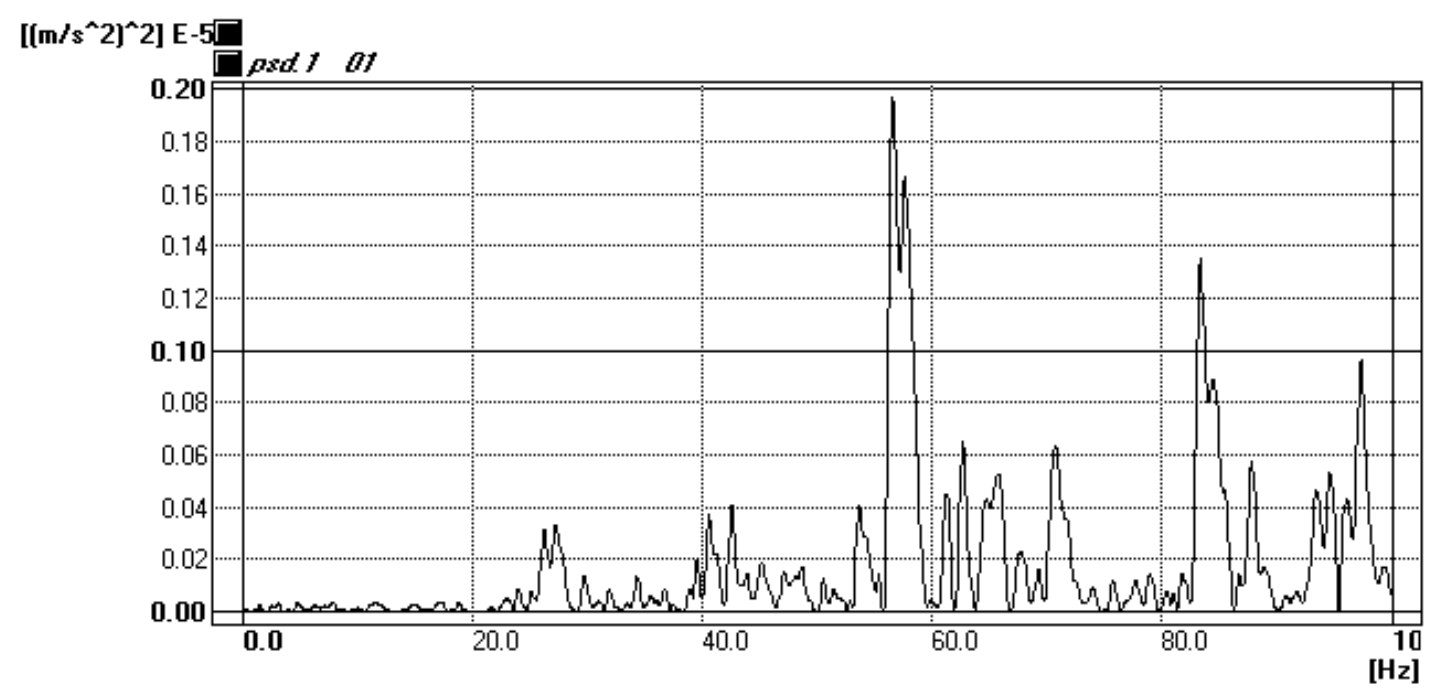

Figure 6. Power spectrum (38.28 km/h, sensor A1, dominant frequency $56.37 \mathrm{~Hz}$ ) 

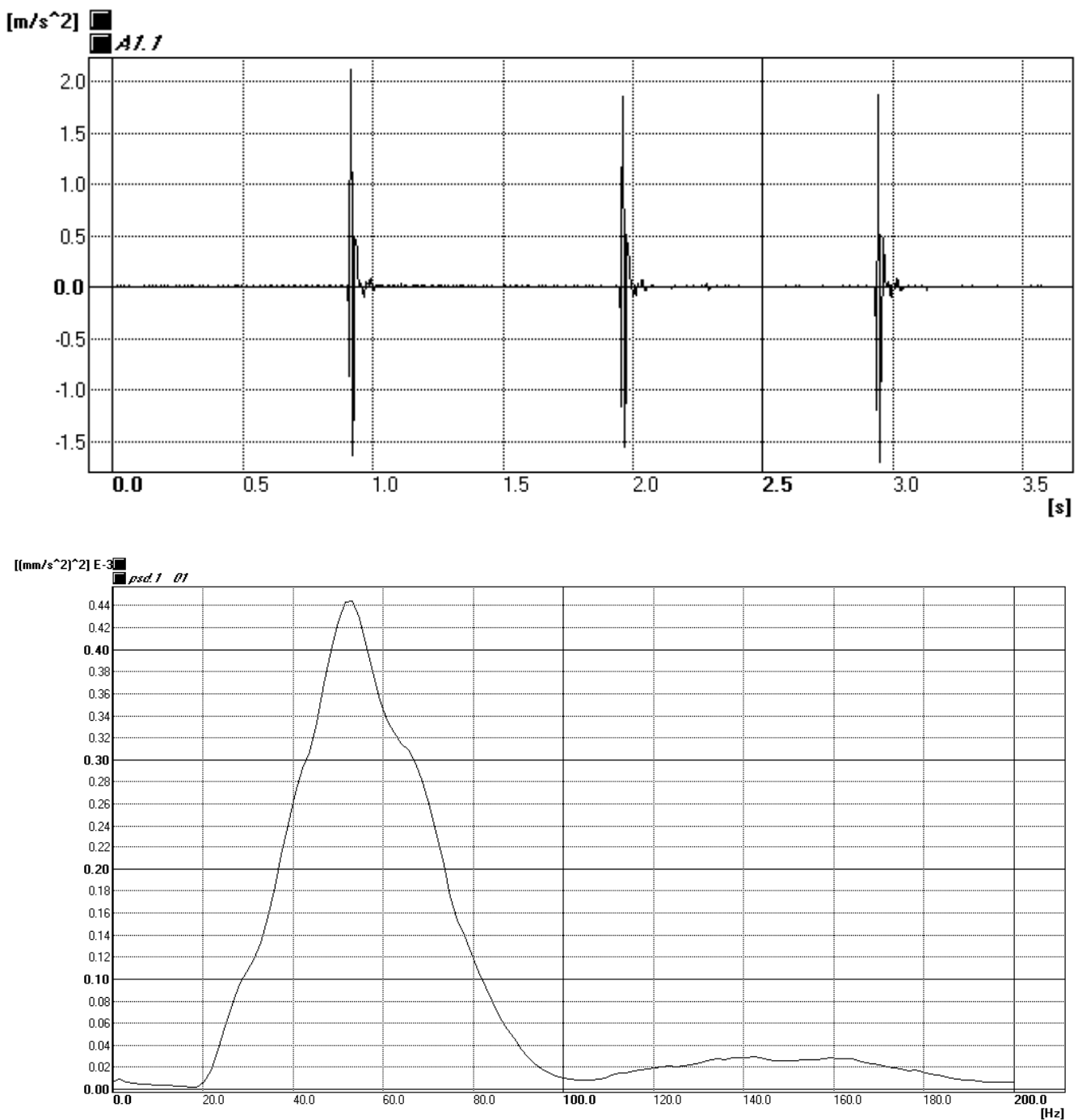

Figure 7. Time history of acceleration and power spectrum (impulse I1, sensor A1, dominant frequency $56.11 \mathrm{~Hz}$ )

\section{Conclusions}

The small channel slabs are used for present high speed rail tracks. For analysis, monitoring and reliability assessment of such slabs the fractal modelling was developed. The input data obtained by experimental measurements in situ were used. The monitoring of actual small channel slab as application is presented. The comparisons have shown good approximation of numerical and experimental results obtained. 

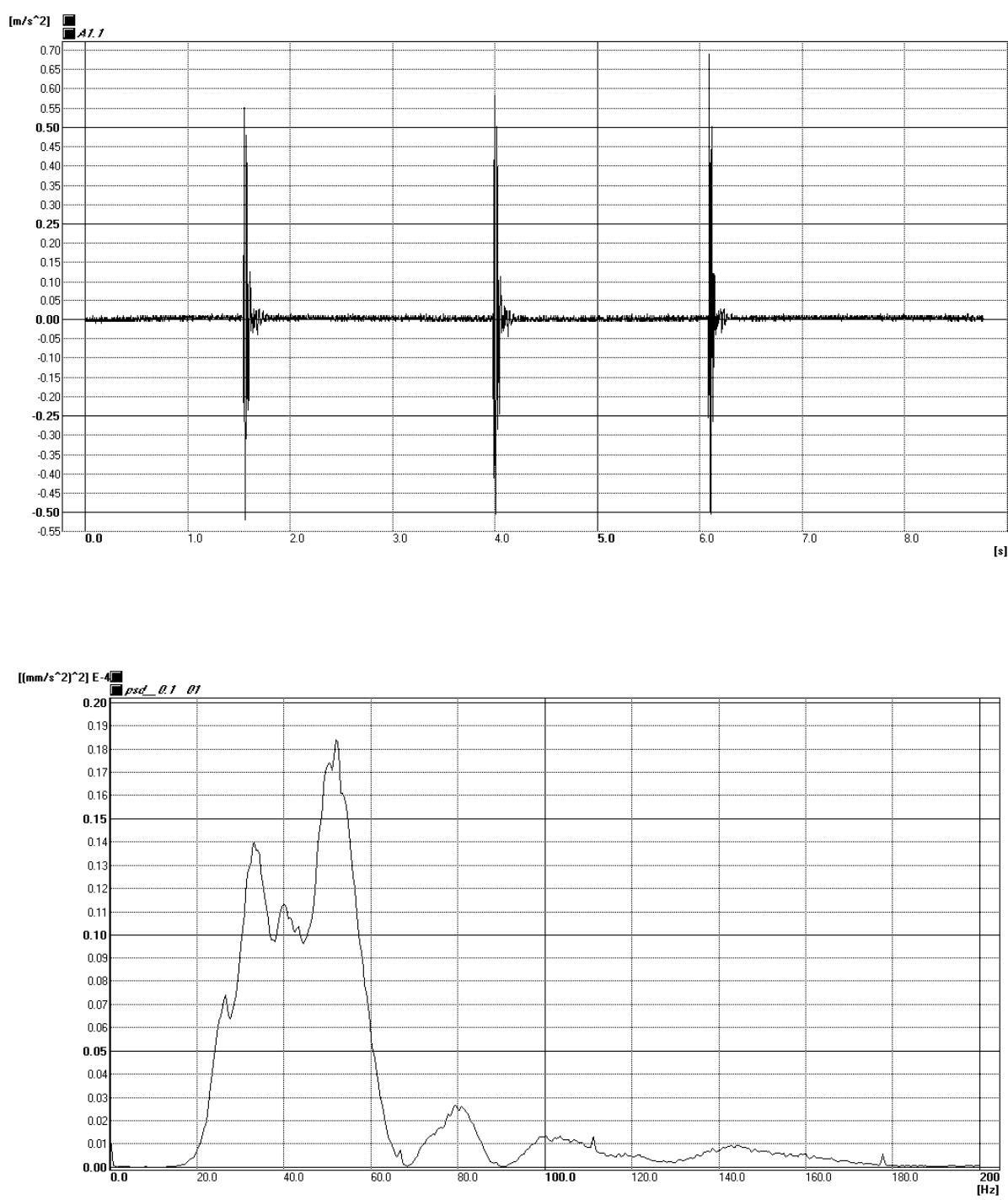

Figure 8. Time history of acceleration and power spectrum (impulse I2, sensor A1, dominant frequency $56.15 \mathrm{~Hz}$ )

\section{Acknowledgements}

Authors are indebted to Slovak Grant Agencies VEGA 2/0143/12 and APVV-0179-10 for supporting research activites reported in this paper. 


\section{REFERENCES}

[1] Chudy, Z. (1984), Japan rails for high velocities, ODIS.

[2] Darr, E. and Fiebig, W. (2006), Feste Fahrbahn - Konstruktion und Bauarten für Eisenbahn und Straßen bahn, Eurailpress.

[3] Epstein, R. (1995), “Werkehrsprojekte Deutsche Einheit un Feste Fahrbahn”, Eisenbahningenieur 46, 26-30.

[4] Kolar, V. and Nemec, I. (1986), Study of new sublayer model. Studie ČSAV 3.86, ACADEMIA, Prague.

[5] Pasternak, P. L. (1956), Basics of new calculation method of structures on elastic sublayer, Trudy MISI, 14, Moscow, Gosstrojizdat.[6] Rail with comprimed layer. Catalogue of Requirements, 1. Issue DB AG, 01/07/94.

[7] Smejkal, J. (1994), “Plate channel slabs with special fixation of rails”, New Railway Technique, 2, 52-54.

[8] Tesar, A. (1985), "Synthesis in optimisation of shell bridge structures”, Building Research Journal, 35, 812-824.

[9] Tesar, A. (1988), Transfer Matrix Method, KLUWER Academic Publishers, Dordrecht/Boston/London.

[10] Tesar, A. (2005), “Load-bearing control of slender bridges”, International Journal for Numerical Methods in Engineering, 62, 924-936. 